\title{
Function-oriented Design of Robust Metal Cocatalyst for Photocatalytic Hydrogen Evolution on Metal/Titania Composites
}

\section{Dong Wang ( $\nabla$ wangd@ecust.edu.cn )}

Centre for Computational Chemistry and Research Institute of Industrial Catalysis, School of Chemistry and Molecular Engineering, East China University of Science and Technology

\section{Xue-Qing Gong}

East China University of Science and Technology https://orcid.org/0000-0002-9566-7427

\section{Article}

Keywords: photocatalytic HER, metal/TiO2, layer-dependent function, electron transfer descriptor, density functional theory

Posted Date: August 13th, 2020

DOI: https://doi.org/10.21203/rs.3.rs-53874/v1

License: (c) (i) This work is licensed under a Creative Commons Attribution 4.0 International License. Read Full License

Version of Record: A version of this preprint was published at Nature Communications on January 8th, 2021. See the published version at https://doi.org/10.1038/s41467-020-20464-x. 


\section{Abstract}

To realize the rational design of improved catalysts is one of ultimate goals in catalysis, though practical strategies are generally in shortage, especially for the complicated photocatalytic processes. Here, we take the hydrogen evolution reaction (HER) as an example, and introduce a theoretical approach for designing robust metal cocatalysts supported on $\mathrm{TiO} 2$, using density functional theory calculations adopting on-site Coulomb correction and/or hybrid functionals. The approach starts with clarifying the individual function of each metal layer of metal/TiO2 composites in photocatalytic HER, covering both the electron transfer and surface catalysis aspects, followed by conducting a function-oriented optimization via exploring competent candidates. With this approach, we successfully determined and verified bimetallic $\mathrm{Pt} / \mathrm{Rh} / \mathrm{TiO} 2$ and $\mathrm{Pt} / \mathrm{Cu} / \mathrm{TiO} 2$ catalysts to be robust substitutes for conventional $\mathrm{Pt} / \mathrm{TiO2}$. The right metal type as well as the proper stacking sequence are demonstrated to be the key to boosting the performance. Moreover, we pioneeringly identified the tunneling barrier height as an effective electron transfer descriptor for photocatalytic reactions on metal/oxide catalysts. We believe that this study pushes forward the frontier of photocatalyst design towards higher water splitting efficiency.

\section{Main Text}

Titanium dioxide $\left(\mathrm{TiO}_{2}\right)$ is an important material for photocatalytic water splitting, ${ }^{1-3}$ on which loading of proper cocatalysts (usually metals) is routinely used to enhance the performance of hydrogen evolution reaction (HER). ${ }^{4,5}$ Since photoelectrons are first generated in the bulk region of $\mathrm{TiO}_{2}$ after photon excitation, ${ }^{6-8}$ good metal/Titania catalysts should qualify at least two aspects of i) efficient electron transfer across the interface (from $\mathrm{TiO}_{2}$ to the metal) and $\mathrm{ii}$ ) rapid $\mathrm{H}_{2}$ production on metal surface. 9,10 Noble metals such as $\mathrm{Pt}, \mathrm{Pd}, \mathrm{Rh}$, are able to meet both requirements, as benefited from their large work functions (or low Fermi levels) ${ }^{4,11}$ and suitable Gibbs adsorption energies of $\mathrm{H}$ atom $\left(\Delta \mathrm{G}_{\mathrm{H}}\right),{ }^{12,13}$ and thus they were frequently used in photocatalytic HER. ${ }^{5,11}$ Particularly, Pt is known as the optimal material for catalyzing HER, ${ }^{4,5,11}$ but how to reduce the catalyst cost and/or increase the activity has aroused significant interests in both academia and industry.

One potential solution is to properly regulate the interface structure. Since the interface bridges the oxide and metals, its structure as well as the metal-support interaction (MSI), ${ }^{14}$ on one hand controls the adhesive contact strength and the electron transfer process, and on the other hand affects the surface reaction activity owing to the induced charge redistributions. ${ }^{15-18}$ Many modification techniques, such as morphology engineering, ${ }^{19,20}$ particle size control ${ }^{21,22}$, alloying ${ }^{23,24}$ etc., are all able to alter the interface properties and furthermore the photocatalytic performance (albeit uncertainty in promotion or not). Nevertheless, in addition to trial-and-error experiments, strategic knowledges about how to conduct rational design of metal/oxide catalysts and where to start are still open questions. Besides, given that the $\Delta G_{H}$ is generally regarded as an effective descriptor signifying surface HER activity, ${ }^{12,13}$ whether there 
also exists some physicochemical properties that could directly scale the electron transfer efficiency remains elusive yet.

Intriguingly, Umezawa et al. investigated electronic structures of metal/ $\mathrm{TiO}_{2}$ composites (metal $=\mathrm{Pt}, \mathrm{Pd}$, $\mathrm{Au}$ ), and found that the MSI induced charge redistribution is largely confined within the first contact metal layer and drops quickly to the second and the third layer. ${ }^{25}$ Similar phenomena have also been observed at other metal/oxide interfaces. ${ }^{26,27}$ These findings imply that each metal layer at the interface is unique and may exhibit distinct catalytic behaviors compared with other layers or bulk metals (i.e., layerdependent catalytic function). Moreover, our previous study on the size effect of supported Pt cocatalysts demonstrated that smaller one-Pt-layer clusters have good electron transfer character but low surface $\mathrm{H}-\mathrm{H}$ coupling activity, whereas larger multilayer particles show an opposite trend with limited electron transfer efficiency. ${ }^{28}$ It was thus anticipated that, i) the interface first metal layer might be related to the electron transfer process while the exterior layer to surface catalytic reactions; ii) further by optimizing the individual function of each layer, the overall performance could be improved.

Herein we report a function-oriented design of efficient metal/ $\mathrm{TiO}_{2}$ catalysts for photocatalytic HER. Differing from the precise size control of Pt nanoparticles to reach a balance between the electron transfer and surface catalysis, ${ }^{28}$ we achieved in theory excellent performance in both aspects (rather than making compromises), by means of alloying robust electron transfer and surface reaction components in a right combination sequence. Furthermore, once the optimal alloying patterns were determined, it is technically feasible to prepare them in experiments at the present stage. ${ }^{29-31}$ For example, Moffat et al. have realized the precise control of the structure and quantity of deposited metals even in the range of monolayer level. ${ }^{23}$

Because Pt is highly effective for surface HER and thus the best candidate for constructing the exterior metal layer, ${ }^{12,13}$ the first priority is to find excellent materials for the interface electron transfer layer. In Figure 1, we assessed the electron transferring ability of 10 candidate metals by calculating the intrinsic electron transfer (IET; in the absence of surface adsorbates) energies from bulk $\mathrm{TiO}_{2}$ to the metal (see sections 1.2 and 1.3 in the supporting information). Note that other transition metals ( $1^{\text {st }} \sim 3^{\text {rd }}$ periods) are generally too active with electron affinity $<1 \mathrm{eV}, 32$ and can readily cause interface distortion (e.g., $\mathrm{Hf}$, $\mathrm{Ta}$ ) and/or oxide reduction (e.g. Ti, Mn, Co, Nb, Mo, W) upon deposition (Figure S2), ${ }^{33}$ and thus were not considered in the screening scope. It was found that noble metals in the VIII group (except Ru) are able to promote the directional electron transfer (namely, from bulk $\mathrm{TiO}_{2}$ to the metal) with exothermic IET energies, but Ag and Au turn to be bad choices, consistent with experimental observations. ${ }^{5,11}$ In particular, the screening results (using the $\mathrm{M}_{8} / \mathrm{TiO}_{2}$ model) suggest that $\mathrm{Rh}$, with strong IET energy of $-0.27 \mathrm{eV}$, might be more efficient than Pt $(-0.17 \mathrm{eV})$ in facilitating the directional electron transfer, but the main drawback is again its high price. Encouragingly, cheap metal $\mathrm{Cu}$ also shows an impressive IET energy of $-0.15 \mathrm{eV}$ close to $\mathrm{Pt}$, serving as a promising electron transfer material. Therefore, we theoretically proposed two bimetallic models, constructed by one layer of noble Rh or cheap Cu directly 
adhering to $\mathrm{TiO}_{2}$ and a second layer of Pt capping on the top, to be competitive substitutes (either in benefits or costs) of the conventional Pt for photocatalytic $\mathrm{H}_{2}$ production.

By utilizing geometry features of the stable $\mathrm{Pt}_{13} / \mathrm{TiO}_{2}$ composite ${ }^{15}$ and replacing the first interface layer of six Pt atoms with $\mathrm{Rh}$ or $\mathrm{Cu}$, we determined the bimetallic structure of $\mathrm{Pt}_{7} \mathrm{Rh}_{6} / \mathrm{TiO}_{2}(101)$ and $\mathrm{Pt}_{7} \mathrm{Cu}_{6} / \mathrm{TiO}_{2}(101)$ via unconstrained relaxations. No obvious structure changes were observed for the $\mathrm{Pt}_{7} \mathrm{Rh}_{6} / \mathrm{TiO}_{2}$ (Figure 2a) relative to that of $\mathrm{Pt}_{13} / \mathrm{TiO}_{2}$, indicating a lattice-matched alloying between $\mathrm{Pt}$ and $\mathrm{Rh}$, whereas noticeable distortions for the $\mathrm{Pt}_{7} \mathrm{Cu}_{6} / \mathrm{TiO}_{2}$ (Figure $2 \mathrm{c}$ ) can be attributed to the distinct atomic radius difference $(\sim 7 \%) .{ }^{34}$ Further IET energy calculations showed that the directional electron transfer (confirmed by charge density plots in Figure S3) indeed gets promoted for both the $\mathrm{Pt}_{7} \mathrm{Rh}_{6} / \mathrm{TiO}_{2}$ and $\mathrm{Pt}_{7} \mathrm{Cu}_{6} / \mathrm{TiO}_{2}$ composites, being -0.04 and $-0.08 \mathrm{eV}$, respectively, as compared with the endothermic 0.05 $\mathrm{eV}$ for $\mathrm{Pt}_{13} / \mathrm{TiO}_{2}{ }^{15,28}$ Such promotion is related to the downward shift of the Fermi level $\left(\mathrm{E}_{\mathrm{f}}\right)$, from $0.45 \mathrm{eV}$ below $\mathrm{TiO}_{2} \mathrm{CBM}$ (conduction band minimum) for $\mathrm{Pt}_{13} / \mathrm{TiO}_{2}{ }^{28}$ to $\sim 0.65 \mathrm{eV}$ (see Figures $2 \mathrm{~b}$ and $2 \mathrm{~d}$ ), considering that a relatively lower energy level is beneficial to accept electrons.

In addition, we also picked a less effective electron transfer metal of Ir for fair comparison, using similar approaches above. Consistently, the $\mathrm{Pt}_{7} \mathrm{Ir}_{6} / \mathrm{TiO}_{2}$ composite (Figure 2e) was found to be no better than $\mathrm{Pt}_{13} / \mathrm{TiO}_{2}$ with an endothermic IET energy of $0.09 \mathrm{eV}$, verifying the effectiveness of our screening approach. Furthermore, we investigated the electron transfer for models with inverted metal stacking sequence, namely the $\mathrm{Rh}_{7} \mathrm{Pt}_{6} / \mathrm{TiO}_{2}$ and $\mathrm{Cu}_{7} \mathrm{Pt}_{6} / \mathrm{TiO}_{2}$ composites (Figures $2 \mathrm{~g}, 2 \mathrm{i}$ ). As expected, the electron transfer process turns to be retarded with endothermic IET energies and up-shifted $E_{f}$ (Figures $2 g-2 j$ ). Despite minor oscillations induced by the upper Rh or Cu layers, the electron transfer ability of the two inverted models generally resembles that of $\mathrm{Pt}_{13} / \mathrm{TiO}_{2}$. These results revealed evidently the electron transfer function of the first interface metal layer, and demonstrated that not only the right metal type (Rh or $\mathrm{Cu}$ ) but also proper stacking sequence $\left(\mathrm{Pt} / \mathrm{Rh} / \mathrm{TiO}_{2}, \mathrm{Pt} / \mathrm{Cu} / \mathrm{TiO}_{2}\right)$ are essential to achieve improved electron transfer efficiency.

Next, it is necessary to verify whether the catalytically efficient HER continues to proceed on the exterior Pt layer of the bimetallic composites. Given the diverse adsorption sites on metal (sub)nanoparticles, we selected two of the most reactive sites (see details in Table S2) for computing the $\mathrm{H}-\mathrm{H}$ coupling barrier $\left(E_{\mathrm{a}}{ }^{\text {coup }}\right)$ and determining the HER activity of the alloy models. In Figures $3 \mathrm{a}$ and $3 \mathrm{~b}$, one can see that both $\mathrm{Pt}_{7} \mathrm{Rh}_{6} / \mathrm{TiO}_{2}$ and $\mathrm{Pt}_{7} \mathrm{Cu}_{6} / \mathrm{TiO}_{2}$ give moderate hydrogen adsorption strength close to the volcano peak of $\Delta \mathrm{G}_{\mathrm{H}}=0 \mathrm{eV} .{ }^{9,10}$ Moreover, we determined the coupling barrier $E_{\mathrm{a}}{ }^{\text {coup }}$ to be 0.71 and $0.69 \mathrm{eV}$ for $\mathrm{Pt}_{7} \mathrm{Rh}_{6} / \mathrm{TiO}_{2}$ and $\mathrm{Pt}_{7} \mathrm{Cu}_{6} / \mathrm{TiO}_{2}$ (Figures 3d, 3f), respectively, being even slightly lower than the value of $0.75 \mathrm{eV}$ on $\mathrm{Pt}_{13} / \mathrm{TiO}_{2}{ }^{28}$ Note that the coupling state on $\mathrm{Pt}_{7} \mathrm{Rh}_{6} / \mathrm{TiO}_{2}$ shows quite late transition structure resembling the $\mathrm{H}_{2}$ adsorption configuration, which was further confirmed by using the climbing image nudged elastic band method (Cl-NEB; Figure S4). ${ }^{35}$ Apparently, the HER activity on these alloy cocatalysts 
could be higher than extended Pt surfaces, owing to large $E_{\mathrm{a}}$ coup of 0.88 and $1.07 \mathrm{eV}$ on $\mathrm{Pt}(111), \mathrm{Pt}(100)$, respectively. ${ }^{36}$

Hence, by integrating good surface catalytic activity of $\mathrm{Pt}$ and robust electron transfer ability of $\mathrm{Rh}$ or $\mathrm{Cu}$, the alloyed $\mathrm{Pt} / \mathrm{Rh}$ or $\mathrm{Pt} / \mathrm{Cu}$ cocatalyst breaks the intrinsic constraints between the two key photocatalytic factors for mono-type materials (e.g. Pt), and could in principle achieve superior performance than conventional $\mathrm{Pt} / \mathrm{TiO}_{2}$. Note that this strategy resembles the concept of using multiphase materials to break the scaling constraint between chemisorption energies of key intermediates (e.g. C and $\mathrm{O}$ in $\mathrm{CO}$ oxidation) in heterogenous catalysis, ${ }^{37}$ and also offers probabilities to approach the global activity maximum in photocatalysis. Particularly, we underline the striking results of $\mathrm{Pt} / \mathrm{Cu} / \mathrm{TiO}_{2}$ with enhanced photocatalytic performance but reduced catalyst cost as compared to pure Pt cocatalysts. This is further validated by using a trilayer $\mathrm{Pt}_{6} \mathrm{Cu}_{13} / \mathrm{TiO}_{2}$ model with much lower Pt content, where suitable $\Delta \mathrm{G}_{\mathrm{H}}$ and $E_{\mathrm{a}}$ coup are still well conserved (Figures $3 \mathrm{c}, 3 \mathrm{f}$ ). Furthermore, the $\mathrm{Pt} / \mathrm{Cu} / \mathrm{TiO}_{2}$ composite was validated to be fairly stable via long-time ab initio molecular dynamics (AIMD) simulations ( $>20$ ps; Figure S5). Overall, $\mathrm{TiO}_{2}$ supported $\mathrm{Cu}$ nanoparticles coated with a thin film of Pt skin are theoretically predicted to be efficient yet inexpensive catalysts for photocatalytic HER.

Finally, given the crucial role of electron transfer in photocatalysis, one may ask what physical properties might be related with the electron transfer efficiency across the interface. Here we calculated the effective potential, which represents the carrier interaction with other electrons in the system and the external electrostatic field, ${ }^{38,39}$ of relevant metal/ $/ \mathrm{TiO}_{2}$ composites using the HSE06 functional (Table S1). Particularly, the tunneling barrier height $\left(\Phi_{\mathrm{TB}}\right)$, defined as the potential difference between the peak at the interface and $\mathrm{TiO}_{2}$ slab (Figure 4a), indicates the minimum energy cost of directional electronic injection via quantum tunneling. ${ }^{38,39}$ Intriguingly, despite typically mentioned in van der Waals junctions (e.g., metal/MoS 2 interfaces), ${ }_{1}^{40}$ the $\Phi_{\text {Тв }}$ was found correlated well with the IET energies among a wide range of metal/ $/ \mathrm{TiO}_{2}$ composites (Figure $4 \mathrm{~b}$ ). As far as we know, this is the first piece of report on the electron transfer descriptor for photocatalytic reactions on metal/oxide catalysts. Considering the significance of electron transfer efficiency in photocatalysis, this finding could possibly promote future photocatalysts design via coordinating conventional catalytic descriptors (e.g., $\Delta G_{H}$ for HER) and the electron transfer properties $\Phi_{\mathrm{TB}}$.

In summary, we decomposed the complicated photocatalytic HER (after photoexcitation) into elementary processes of interface electron transfer and surface catalytic reactions in this work. For metal/ $\mathrm{TiO}_{2}$ composites, the interfacial first metal layer was evidenced to be responsible for collecting photoelectrons from $\mathrm{TiO}_{2}$, while the exterior layer is largely related to catalysing surface HER. Regarding particularly the former, we theoretically identified $\mathrm{Rh}$ and $\mathrm{Cu}$ to be robust electron transfer materials, which, after alloying with the optimal HER catalyst of $\mathrm{Pt}$, give rise to bimetallic $\mathrm{Pt} / \mathrm{Rh} / \mathrm{TiO}{ }_{2}$ and $\mathrm{Pt} / \mathrm{Cu} / \mathrm{TiO}_{2}$ as excellent substitutes for the conventional $\mathrm{Pt} / \mathrm{TiO}_{2}$. Our results demonstrated clearly the importance of both the right metal type and the proper stacking sequence in improving the performance of alloyed materials. We 
furthermore generalized a linear correlation between IET energies and the tunneling barrier height $\Phi_{\mathrm{TB}}$ of metal/ $/ \mathrm{TiO}_{2}$ composites, paving the way to the rational design of highly-efficient and cost-effective photocatalysts, for instance, the proposed $\mathrm{Pt} / \mathrm{Cu} / \mathrm{TiO}_{2}$ for photocatalytic hydrogen production.

\section{Declarations}

\section{Conflicts of interest}

There are no conflicts to declare.

\section{Acknowledgements}

The authors acknowledge the financial support from the National Key Research and Development Program of China (2018YFA0208602), the National Natural Science Foundation of China (21903025, 21825301), Shanghai Municipal Science and Technology Major Project (2018SHZDZX03) and Shanghai Science and Technology Committee (17520750100).

\section{References}

(1) Chen, X.; Mao, S. S. Chem. Rev. 2007, 107, 2891.

(2) De Angelis, F.; Di Valentin, C.; Fantacci, S.; Vittadini, A.; Selloni, A. Chem. Rev. 2014, 114, 9708.

(3) Thompson, T. L.; Yates, J. T., Jr. Chem. Rev. 2006, 106, 4428.

(4) Yang, J.; Wang, D.; Han, H.; Li, C. Accounts Chem. Res. 2013, 46, 1900.

(5) Ran, J.; Zhang, J.; Yu, J.; Jaroniec, M.; Qiao, S. Z. Chem. Soc. Rev. 2014, 43, 7787.

(6) Zhang, Z.; Yates, J. T. J. Phys. Chem. C 2010, 114, 3098.

(7) Thompson, T. L.; Yates, J. T. J. Phys. Chem. B 2005, 109, 18230.

(8) Di Valentin, C.; Selloni, A. J. Phys. Chem. Lett. 2011, 2, 2223.

(9) Patrocinio, A. O. T.; Schneider, J.; França, M. D.; Santos, L. M.; Caixeta, B. P.; Machado, A. E. H.; Bahnemann, D. W. RSC Adv. 2015, 5, 70536.

(10) Cowan, A. J.; Tang, J. W.; Leng, W. H.; Durrant, J. R.; Klug, D. R. J. Phys. Chem. C 2010, 114, 4208.

(11) Ni, M.; Leung, M. K. H.; Leung, D. Y. C.; Sumathy, K. Renew. Sust. Energ. Rev. 2007, 11, 401. 
(12) Nørskov, J. K.; Bligaard, T.; Logadottir, A.; Kitchin, J. R.; Chen, J. G.; Pandelov, S.; Stimming, U. J. Electrochem. Soc. 2005, 152, J23.

(13) Greeley, J.; Jaramillo, T. F.; Bonde, J.; Chorkendorff, I. B.; Norskov, J. K. Nat. Mater. 2006, 5, 909.

(14) Tauster, S. Accounts Chem. Res. 1987, $20,389$.

(15) Wang, D.; Liu, Z. P.; Yang, W. M. ACS Catal. 2017, 7, 2744.

(16) Klyushin, A. Y.; Greiner, M. T.; Huang, X.; Lunkenbein, T.; Li, X.; Timpe, O.; Friedrich, M.; Hävecker, M.; Knop-Gericke, A.; Schlögl, R. ACS Catal. 2016, 6, 3372.

(17) Wang, Y. G.; Yoon, Y.; Glezakou, V. A.; Li, J.; Rousseau, R. J. Am. Chem. Soc. 2013, 135, 10673.

(18) Muhich, C. L.; Zhou, Y.; Holder, A. M.; Weimer, A. W.; Musgrave, C. B. J. Phys. Chem. C 2012, $116,10138$.

(19) Karan, H. I.; Sasaki, K.; Kuttiyiel, K.; Farberow, C. A.; Mavrikakis, M.; Adzic, R. R. ACS Catal. 2012, 2, 817.

(20) Lee, K. S.; Yoo, S. J.; Ahn, D.; Jeon, T. Y.; Choi, K. H.; Park, I. S.; Sung, Y. E. Langmuir 2011, 27, 3128.

(21) Yu, J.; Qi, L.; Jaroniec, M. J. Phys. Chem. C 2010, 114, 13118.

(22) Xing, J.; Jiang, H. B.; Chen, J. F.; Li, Y. H.; Wu, L.; Yang, S.; Zheng, L. R.; Wang, H. F.; Hu, P.; Zhao, H. J.; Yang, H. G. J. Mater. Chem. A 2013, 1, 15258.

(23) Liu, Y.; Gokcen, D.; Bertocci, U.; Moffat, T. P. Science 2012, 338, 1327.

(24) Li, M.; Ma, Q.; Zi, W.; Liu, X.; Zhu, X.; Liu, S. F. Sci. Adv. 2015, 1, e1400268.

(25) Chen, H.; Li, P.; Umezawa, N.; Abe, H.; Ye, J.; Shiraishi, K.; Ohta, A.; Miyazaki, S. J. Phys. Chem. C 2016, 120, 5549.

(26) Born, M. Ann. Phys. 1927, 84, 457.

(27) Hohenberg, P. Phys. Rev. 1964, 136, 864B.

(28) Wang, D.; Liu, Z. P.; Yang, W. M. ACS Catal. 2018, 8, 7270.

(29) Asano, M.; Kawamura, R.; Sasakawa, R.; Todoroki, N.; Wadayama, T. ACS Catal. 2016, 5285.

(30) Čolić, V.; Bandarenka, A. S. ACS Catal. 2016, 5378. 
(31) Calle-Vallejo, F.; Koper, M. T.; Bandarenka, A. S. Chem. Soc. Rev. 2013, 42, 5210.

(32) Linstrom P. J., Mallard W. G., Eds., NIST Chemistry WebBook, NIST Standard Reference Database Number 69, National Institute of Standards and Technology, Gaithersburg MD, 20899, https://doi.org/10.18434/T4D303, (retrieved May 2, 2020).

(33) Chen, X.; Shen, S.; Guo, L.; Mao, S. S. Chem. Rev. 2010, 110, 6503.

(34) Ruban, A. V.; Skriver, H. L.; Nørskov, J. K. Phys. Rev. B 1999, 59, 15990.

(35) Henkelman, G.; Uberuaga, B. P.; Jónsson, H. J. Chem. Phys. 2000, 113, 9901.

(36) Wei, G.-F.; Liu, Z.-P. Chem. Sci. 2015, 6, 1485.

(37) Cheng, J.; Hu, P. J. Am. Chem. Soc. 2008, 130, 10868.

(38) Shen, T.; Ren, J. C.; Liu, X.; Li, S.; Liu, W. J. Am. Chem. Soc. 2019, 141, 3110.

(39) Kang, J.; Liu, W.; Sarkar, D.; Jena, D.; Banerjee, K. Phys. Rev. X 2014, 4.

(40) Gong, C.; Colombo, L.; Wallace, R. M.; Cho, K. Nano Lett. 2014, 14, 1714.

\section{Figures}



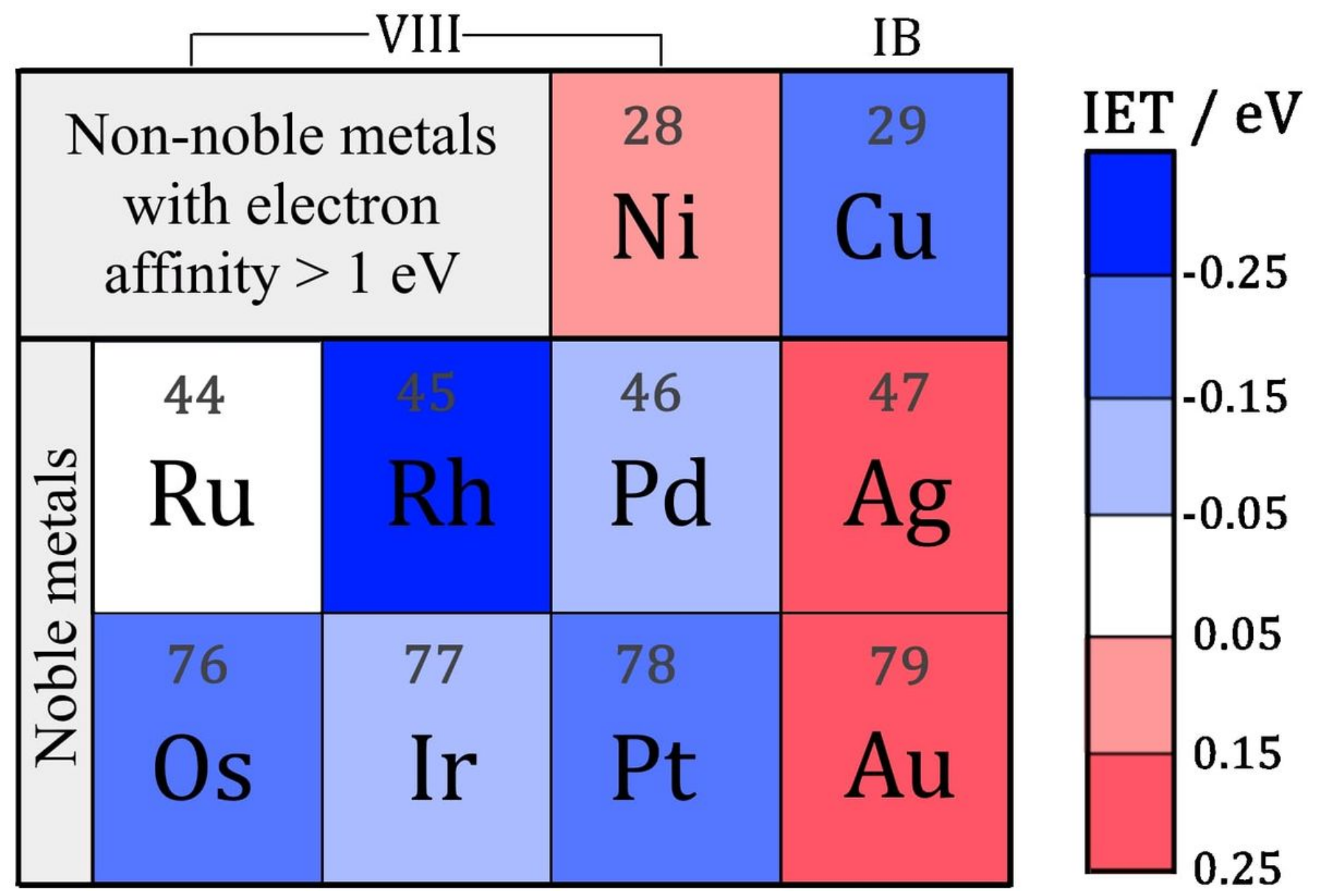

Figure 1

Schematic of calculated IET energies in the presence of different metals on TiO2 using M8/TiO2 or $\mathrm{M} 7 / \mathrm{TiO} 2$ models. Colors from red to blue indicate gradually enhancing IET energies, and the details are shown in Table S1 and Figure S1. 

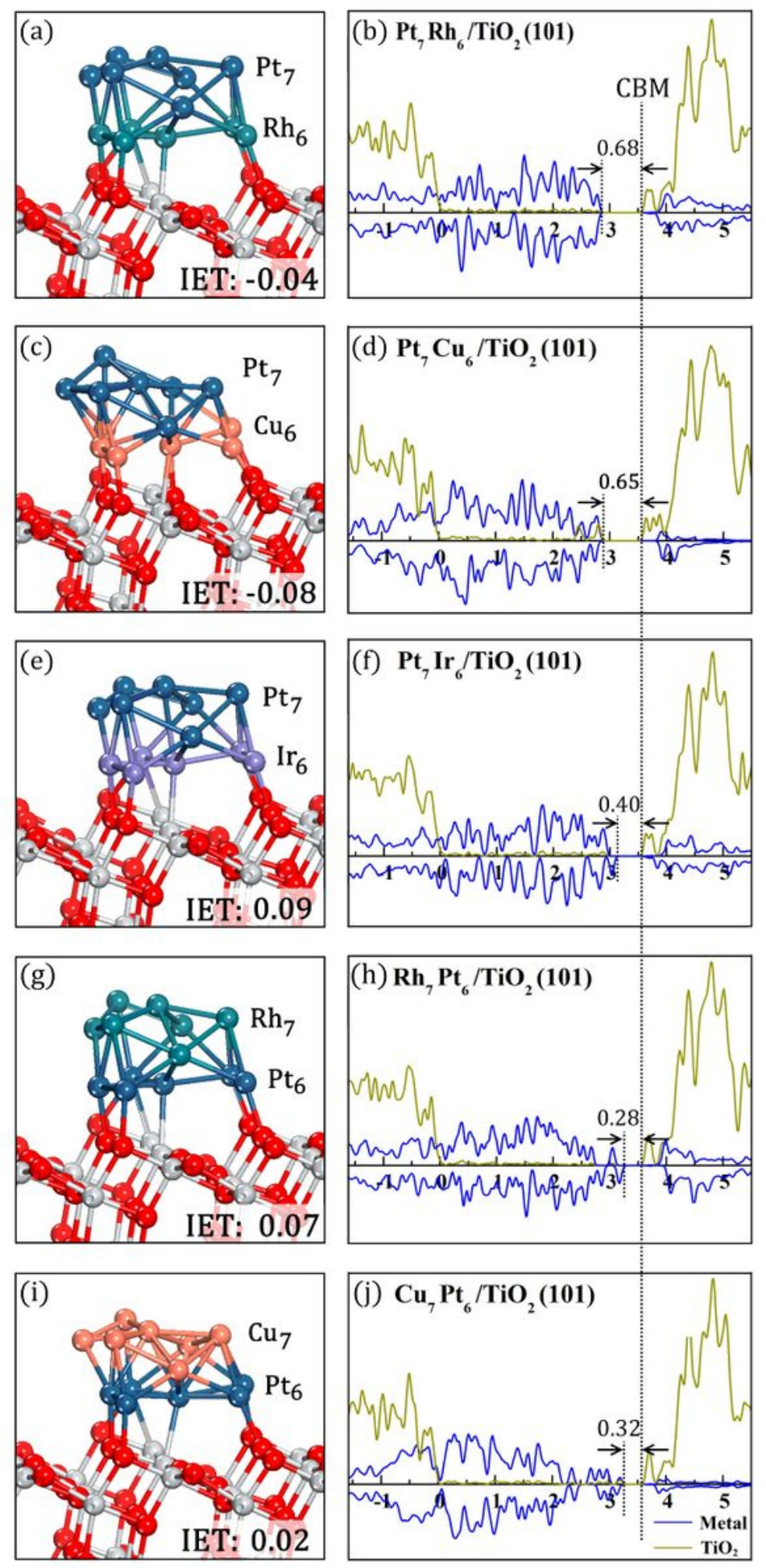

\section{Figure 2}

Calculated structures and density of states (DOS; using the hybrid HSEO6 functional) for $(a, b)$ Pt7Rh6/TiO2(101), (c,d) Pt7Cu6/TiO2(101), (e,f) Pt7lr6/TiO2(101), (g,h) Rh7Pt6/TiO2(101) and (i,j) Cu7Pt6/TiO2(101) composites, respectively. The DOS for M13 cluster and for TiO2 surface are represented by blue and yellow-green curves, respectively. The valance band edge of $\mathrm{TiO} 2$ is uniformly 
aligned to zero in DOS, and the vertical dot lines indicate the TiO2 CBM and the Ef position, respectively. Calculated IET energies are also given in $\mathrm{eV}$.
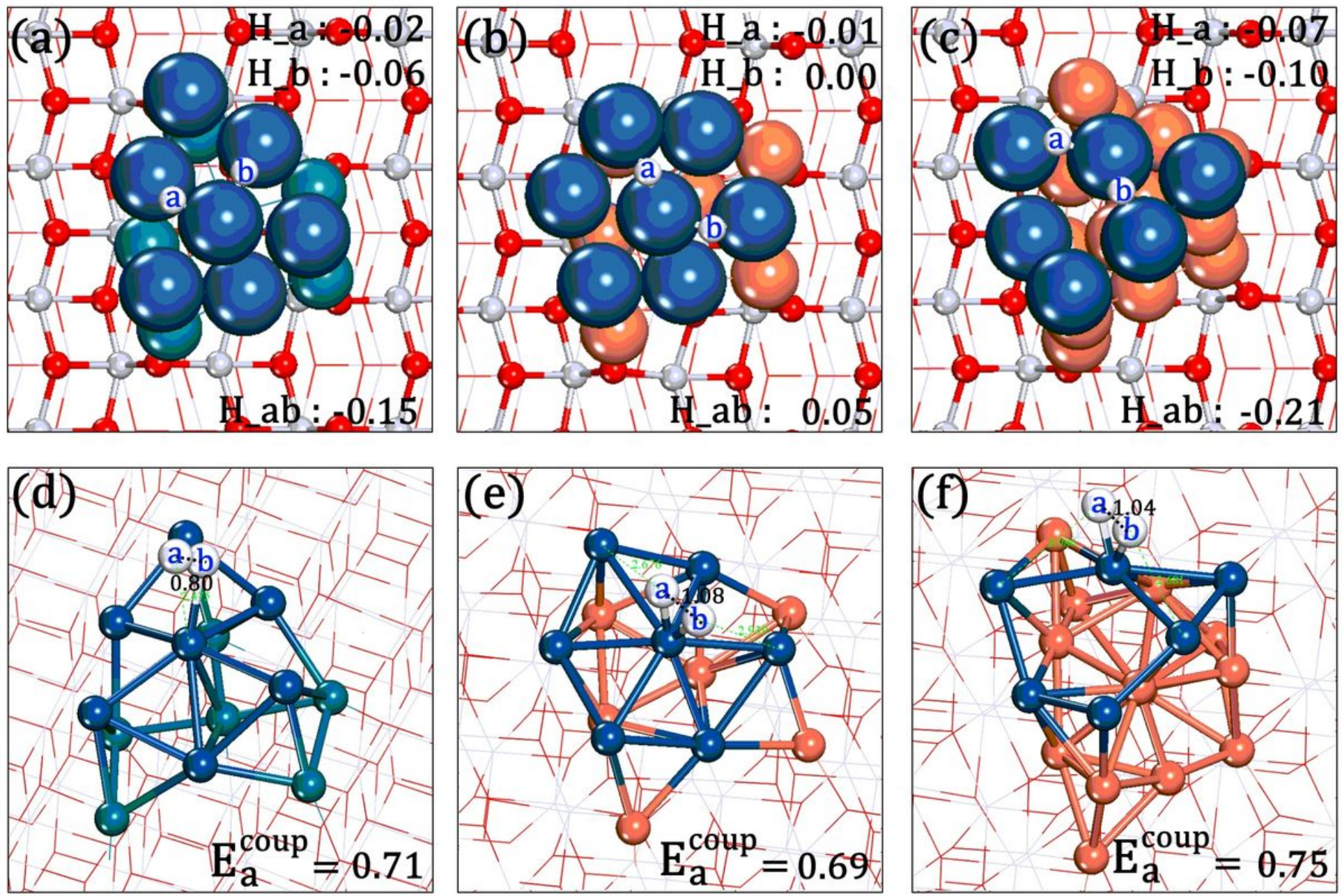

Figure 3

Calculated structures for (a-c) $\mathrm{H}$ adsorption at two reactive sites (labelled as a and b) and (d-f) transition states of $\mathrm{H}-\mathrm{H}$ coupling on the Pt7Rh6/TiO2, Pt7Cu6/TiO2 and Pt6Cu13/TiO2 composites, respectively. Gibbs adsorption energies for the independent adsorption of $\mathrm{H}$ atom on each of the two reactive sites $\left(\mathrm{H} \_a\right.$ and $\left.\mathrm{H}_{-} b\right)$, the co-adsorption of two $\mathrm{H}$ atoms $\left(\mathrm{H}_{-} \mathrm{ab}\right)$, as well as the $\mathrm{H}-\mathrm{H}$ coupling barrier, are given in eV. 

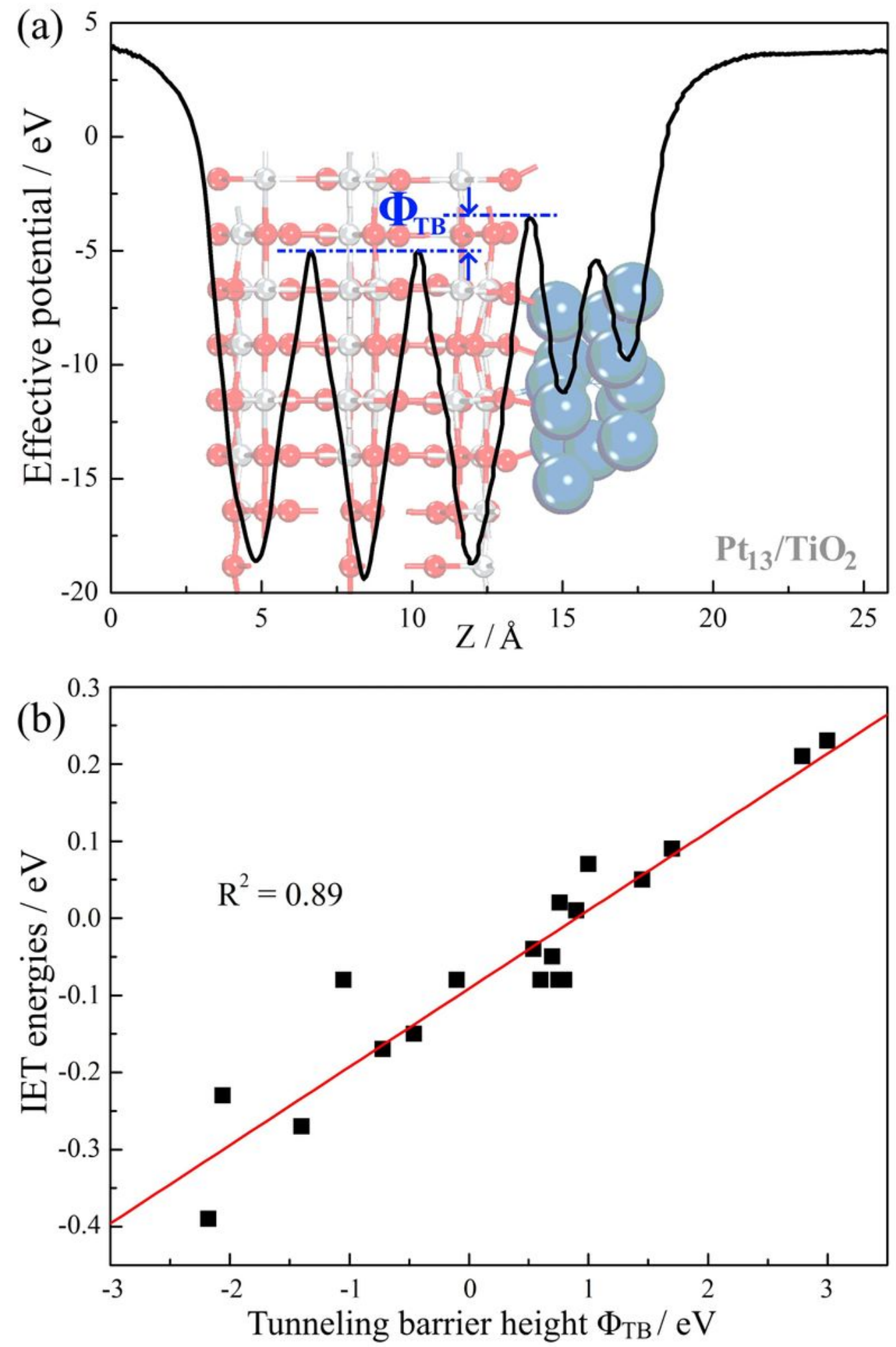

Figure 4

(a) Schematic of the effective potential (black curve) and ФTB (indicated by blue arrows) of Pt13/TiO2 using the hybrid HSE06 functional, as well as (b) the linear correlation between IET energies and ФTB on a wide range of metal/TiO2 composites. 


\section{Layer-dependent catalytic function}

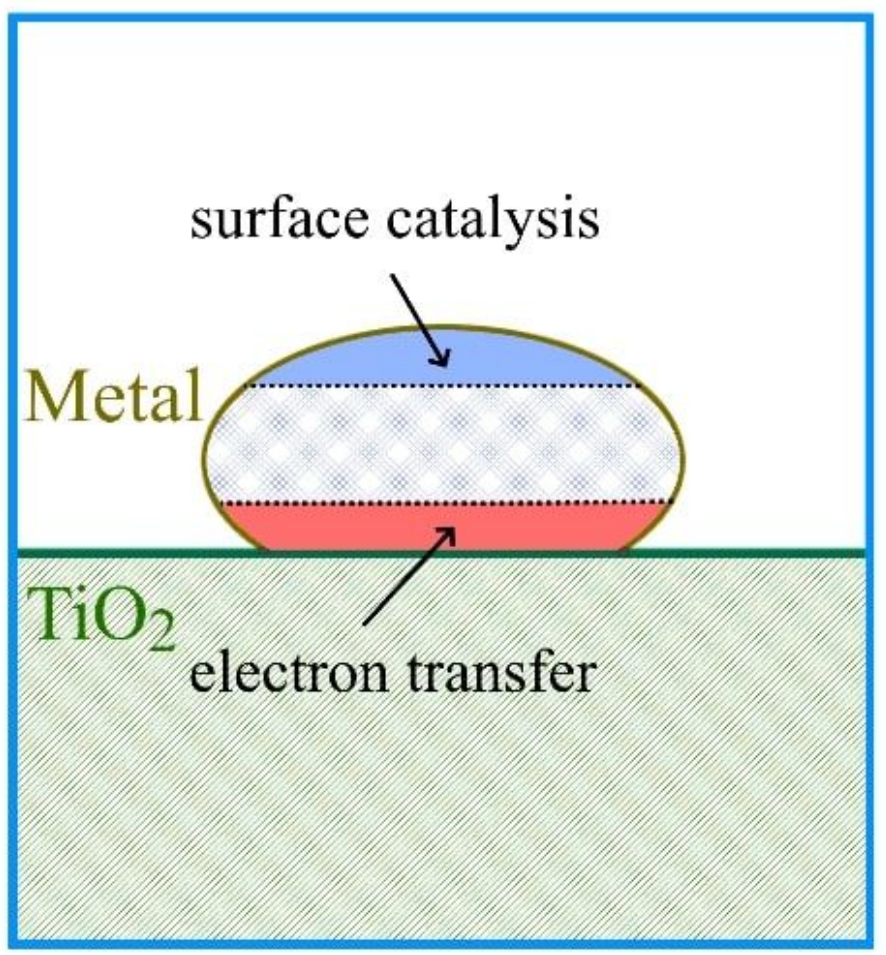

2.Function-oriented catalyst design

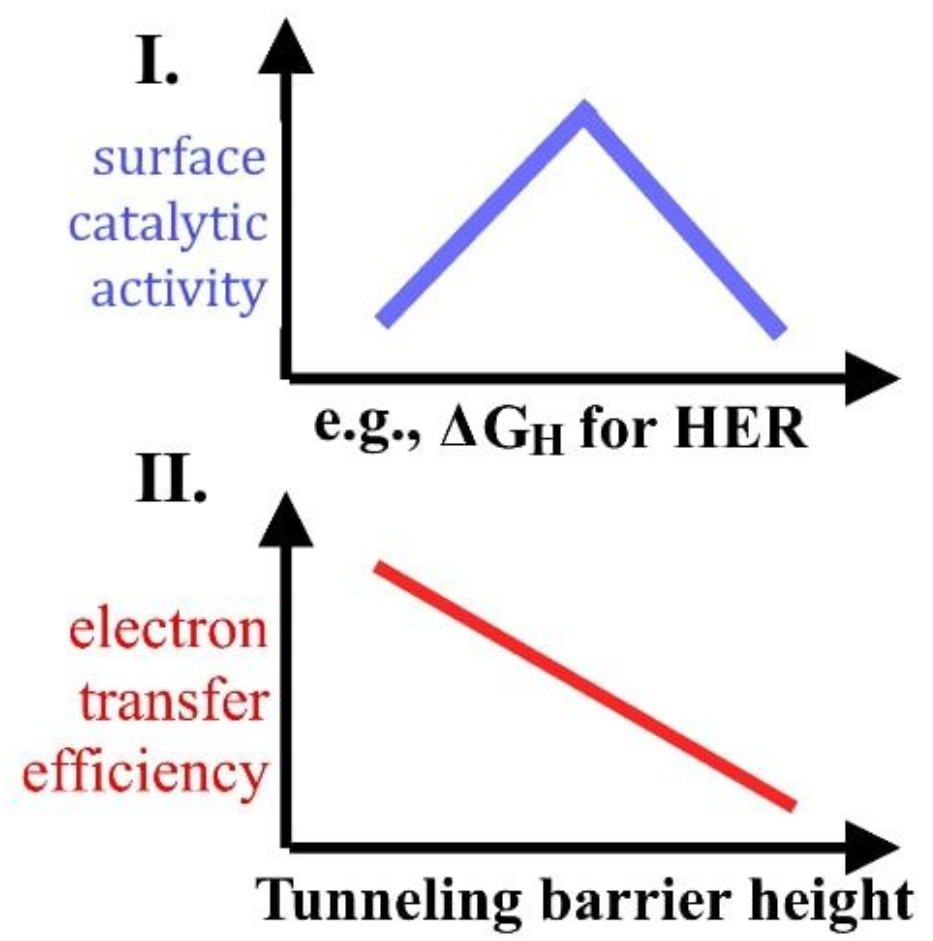

Figure 5

Table of Contents Graphic

\section{Supplementary Files}

This is a list of supplementary files associated with this preprint. Click to download.

- Supplementarylnformation.pdf 